\title{
Modeling the distribution of the North Atlantic right whale Eubalaena glacialis off coastal Maine by areal co-kriging
}

\author{
Brooke Wikgren ${ }^{1, *}$, Hauke Kite-Powell ${ }^{2}$, Scott Kraus ${ }^{1}$ \\ ${ }^{1}$ New England Aquarium, John H. Prescott Marine Laboratory, Central Wharf, Boston, Massachusetts 02110, USA \\ ${ }^{2}$ Woods Hole Oceanographic Institution, Marine Policy Center, MS 41, Woods Hole, Massachusetts 02543, USA
}

\begin{abstract}
To enhance recovery of the Endangered North Atlantic right whale Eubalaena glacialis, mitigation strategies are needed to reduce the leading causes of injury and mortality of these animals, which include ship strikes and entanglement in fishing gear. Such efforts require information on the spatial and temporal distribution of right whales that can be analyzed against risk factors to identify solutions to protect whales while minimizing economic impacts to industry. Currently, no methods adequately make use of all available data to characterize right whale distribution, often leaving data gaps or misrepresenting whale activity in areas where we have limited systematic survey data. In response to this, an areal co-kriging interpolation technique was developed using ArcGIS 10.1 Geostatistical Analyst, utilizing all available right whale location data including systematic survey data, opportunistic sightings data, and satellite tag data. With many management plans shaped around specific geographic zones, this methodology was developed with the option to summarize information within user-defined polygons depending on the management regime. For this paper, whale distribution predictions were summarized to 524 irregularly shaped polygons off coastal Maine, representing lobster fishing zones at a 2 mo temporal scale. Results indicate that the predicted values fall within reasonable ranges, appropriately represent seasonal differences, and better represent right whale distribution patterns compared to other methods.
\end{abstract}

KEY WORDS: Right whale $\cdot$ Spatial distribution $\cdot$ Conservation $\cdot$ Cetacean abundance $\cdot$ Endangered species $\cdot$ Habitat-based density model $\cdot$ Marine mammal $\cdot$ Modeling $\cdot$ Wildlife management

\section{INTRODUCTION}

\section{Purpose and background}

The North Atlantic right whale Eubalaena glacialis is an Endangered species (Reilly et al. 2012) with an estimated population of 490 individuals (Pettis 2011). Ship strikes and entanglement in fishing gear are the leading sources of direct human injury to and mortality of these whales (Knowlton \& Kraus 2001, Kraus et al. 2005, van der Hoop et al. 2013). Due to the small number of individuals, a single mortality has a signif- icant impact on the population; therefore, mitigating these anthropogenic risks is vital to the survival of the species (Fujiwara \& Caswell 2001).

For effective mitigation, it is necessary for management strategies to be based on comprehensive right whale distribution data that is both spatially and temporally explicit. By quantifying the species distribution in both space and time, it is possible to assess spatial and temporal risk from shipping and fishing, the 2 main anthropogenic sources of right whale mortality. This approach was illustrated in the successful shipping lane movements in the Bay of Fundy, Stell- 
wagen Bank, and Cape Cod Bay, which have been shown to achieve statistically significant reductions in expected ship strike risk to right whales by minimally shifting traffic lanes (Brown 2002, Nichols \& Kite-Powell 2005, Provincetown Center for Coastal Studies 2009).

While species mapping techniques currently exist, no established methods adequately make use of all available data or sufficiently characterize right whale distribution for these purposes. To fill this data gap, we developed a methodology to create a series of spatio-temporal right whale distribution maps, utilizing all available data, that can be summarized into user-defined bounded polygons. Polygons serve as a good means of summarizing whale activity and supporting conflict mitigation, as many management plans are bounded by discrete zonal areas.

\section{Current practices and methodology considerations}

The modeling techniques used in the development of species distribution models are constrained by the data available. Available marine animal data typically fall within 1 of 2 categories: (1) presenceonly data (referred to in this paper as off-effort records) or (2) count records associated with systematic survey effort that can generate some proportional rate of occupancy (referred to in this paper as on-effort records). The term on-effort is applied to sightings collected while observers were actively looking for the species in question, and include records of effort exerted, such as time or distance traveled, used to normalize the number of sightings (on-effort). Off-effort data is obtained from passive or opportunistic sightings with no associated data on search effort (e.g. by whale watchers or fishermen). For the species in this study, Eubalaena glacialis, the data available consists of both on-effort (including systematic survey data) and off-effort data (including survey data that does not meet 'on-effort' requirements, opportunistic sightings, and satellite tag data locations).

One widely used method for mapping marine mammal distribution uses on-effort systematic survey data only, normalizing animal count data by the amount of effort exerted, resulting in sightings per unit effort (SPUE). This method, however, can only represent the distribution for areas covered by survey effort. Right whale surveys have generally focused on select habitat areas and times throughout the year where whales have been known to be present, with little or no survey effort in other areas, par- ticularly inshore areas. The occurrence of spatial and temporal gaps in survey effort therefore limits the utility of strictly on-effort SPUE analyses, which discount off-effort sightings in non-surveyed areas, effectively ignoring species presence in some areas where we know they occur. In our study area (Fig. 1), there have been ca. 3700 right whale sightings considered on-effort (included in on-effort SPUE analyses) and ca. 3100 off-effort sightings (1966 to 2010) (Supplement 1 at www.int-res.com/articles/suppl/ n024p021_supp.pdf). When off-effort sightings are ignored, nearly half the data is not being utilized. For example, from April to September, there is little or no survey effort focused on Jeffrey's Ledge off New Hampshire, resulting in on-effort SPUE mappings of 0 in that area. However, the inclusion of presenceonly records verifies that a large number of right whales have been sighted in that area during that time (Supplement 1).

A second approach uses presence-only records, linking the presence of a species with selected environmental variables in which it was found. These types of models are also referred to as habitat suitability models; they typically do not produce species count or density predictions, but generate outputs representing the probability of a species presence/ occurrence based on the combination of appropriate

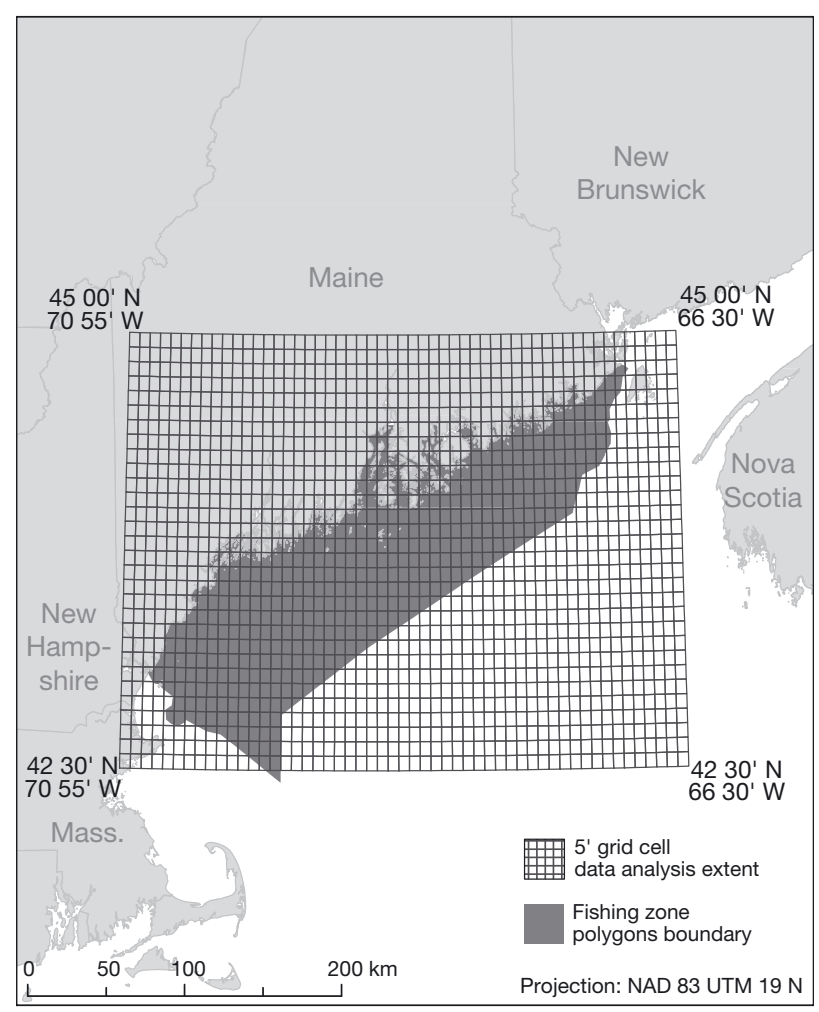

Fig. 1. Study area off coastal Maine, northeastern USA 
covariate ranges (Franklin 2009). However, the characteristics of the marine environment are physically and temporally dynamic; and it can be difficult to establish correlations between species presence and environmental variables (Franklin 2009). Furthermore, the use of this approach, while well-suited for presence-only records which could incorporate all existing data, disregards any effort data associated with the on-effort records. Ideally, a comprehensive spatially and temporally explicit right whale distribution dataset would include all available data, incorporating both on- and off-effort data while keeping as much survey effort information as possible. Such an approach was suggested by Kenney in his analysis for estimating minimum on-effort SPUE values for right whales and humpback whales in areas with low survey effort (Kenney 2012).

In addition to the challenge of integrating on- and off-effort data, the characteristics of the data determine statistical assumptions and the appropriateness of different modeling techniques. The on-effort data, common with many ecological data sets, contain many zero values (Martin et al. 2005), do not fit a standard Poisson distribution, and suffer from overdispersion (Martin et al. 2005). 'Zero inflation' datasets have both 'true-zero counts' due to (1) lack of occurrence due to the ecological processes or (2) heterogeneity in distribution, and 'false-zero counts' due to (1) the species not being present during the survey period or (2) the species being present but not detected (Martin et al. 2005). Most wildlife data contains a mixture of both true- and false-zero counts. Overdispersion can also occur when the data are clustered (or spatially autocorrelated), violating the likelihood of independence of observations (Hilbe 2007).

In response to the data considerations outlined above, we created a seasonal set of right whale distributions using an areal co-kriging interpolation technique, incorporating all data (on- and off-effort) and addressing the challenges associated with the data's characteristics.

\section{METHODS}

We performed areal co-kriging interpolation in ArcGIS 10.1 Geostatistical Analyst, applying kriging theory to data that is averaged or aggregated across polygons. Predictive values and their associated standard errors were calculated for all areas within and between input polygons. These predictions were then re-aggregated to a new target set of polygons (Krivoruchko et al. 2011a).
Interpolation is a method of spatial prediction that estimates the values of unsampled locations based on values at sampled locations. In essence, it uses known values at specific locations to fill in the unknown areas, or gaps. Kriging is a type of interpolation that uses statistical models for estimating these spatial variables. Kriging theory is rooted around 3 main elements: (1) spatial trend, in which a variable value increases or decreases based on direction; (2) spatial autocorrelation, based on the idea that points near each other are more similar than those further away; and (3) stochastic variation. An estimation function is developed through a mathematical model combining these 3 components, which is then applied to data at measured locations to predict values of unknown locations throughout a study area (Bolstad 2008).

Traditional kriging techniques require that measured data be collected in points (Krivoruchko et al. 2011a). While this is appropriate for some types of collected data, as measured rainfall at particular sampling locations, it is unsuitable for data that represents measured values that are collected across areas, like in the case of systematic survey data. Areal interpolation, however, differs from traditional kriging techniques. It works by estimating values based on data collected in polygons and predicts values for a new set of polygons in the same data domain that differ in size and shape from the original (Krivoruchko et al. 2011b). To utilize all available data, we used 2 independent areal interpolation models, one for presence-only data, and one for oneffort data, and then integrated the results of both models as described below.

The first was an overdispersed Poisson areal kriging model (OPAKM) (Krivoruchko et al. 2011b) utilizing on-effort data records. The OPAKM allows for polygonal datasets that contain Poisson counts that are overdispersed with differing observation times. As with most wildlife data, our on-effort data is zero inflated, causing it to be overdispersed (see 'Introduction') with each polygon containing differing observation times. Overdispersion, which can also occur when data are clustered (or spatially autocorrelated), was further tested with the Moran's I statistic, which tests for spatial autocorrelation (Bolstad 2008; see Supplement 2 at www.int-res.com/articles/ suppl/n024p021_supp.pdf). The Moran's I statistic showed p-values of 0 and $z$-scores greater than 1.96, showing statistically significant $(95 \%$ CI) spatial autocorrelation across all datasets (see Supplement 3 at www.int-res.com/articles/suppl/n024p021_supp. pdf), thus further indicating overdispersion for the 
on-effort data and the appropriateness of the OPAKM for our data. The OPAKM output constitutes a predictive surface of density of counts at each location within the data extent (Krivoruchko et al. 2011a).

The second areal interpolation model used was a Gaussian areal kriging model (GAKM) (Krivoruchko et al. 2011b) utilizing a probability of presence dataset generated with Maxent ('maximum entropy') software (Phillips et al. 2006). The Maxent program uses presence-only (off-effort) records to estimate a probability of presence distribution based on a multivariate analysis of suitable habitat conditions associated with the species occurrences in environmental feature-space (Phillips \& Dudík 2008, Franklin 2009). The probabilityof-presence distribution outputs were averaged for each input polygon. The GAKM was developed for Gaussian data that is averaged over polygons. The output constitutes a predictive surface of values representing a probability of presence for each location within the data extent (Krivoruchko et al. 2011a).

We performed co-kriging to integrate both of these models together, resulting in a single output. Cokriging works by using a secondary variable that is correlated with the primary variable, using the covariance between the 2 to improve the predictions of the primary variable of interest (Bolstad 2008). Here, co-kriging was performed using the OPAKM output (count density) as the primary variable and the GAKM output (probability of presence) as the secondary variable. This co-kriging technique incorporates both on-effort and off-effort whale sightings data, while keeping effort data intact and accounting for the overdispersed Poisson characteristics of the data.

We used the results of co-kriging interpolation to create a model of right whale distribution on a 2 mo temporal scale, with whale population density predictions summarized to 524 irregularly shaped polygons representing lobster fishing zones off coastal Maine (Brehme et al. in press). We summarized to these polygons for the present study; however, the underlying interpolated distribution can be summarized to any size and/or shape of polygon management zones desired, depending on the needs of the mitigation strategies.

\section{Study area and temporal resolution}

Our study area consists of 524 irregularly shaped polygons covering approximately 50 nautical miles off coastal Maine (polygon outer boundary referenced in Fig. 1). The polygons represent the most detailed fishing effort and gear configuration data compiled for these waters to date (Brehme et al. in press).

Due to sparse right whale count data, we aggregated the right whale data to 2 mo intervals. By matching the spatial patterns of SPUE for sequential months (Supplement 4 at www.int-res.com/articles/ suppl/n024p021_supp.pdf), the 2 mo aggregations were designed to increase the count data to inform our predictive map, while also being representative of each month if it were to stand alone. Those combinations were: February/March, April/May, June/July, August/September, October/November, and December/January (Supplement 1). All methods described in this paper were completed at these aggregations.

\section{On-effort data}

We obtained survey-based data from the North Atlantic Right Whale Consortium (NARWC) database (NARWC 2012). Criteria required for the survey to be considered 'on-effort' have been described by Kenney (2010), using only data obtained in Beaufort sea-state 4 and below, appropriate for use of large whales (Pike et al. 2009, Paxton et al. 2011). Additional information on survey design and data quality control can be found in Kenney (2010).

We summarized this data per month to $5 \times 5^{\prime}$ grid cell polygons (Fig. 1). Relevant table fields included (1) sum number of on-effort whales sighted, (2) sum of on-effort survey trackline (km), and (3) SPUE, calculated from the number of on-effort whales sighted divided by the sum of on-effort survey trackline. To create 2 mo aggregations (described in the above section), we summed the number of whales sighted and on-effort survey trackline $(\mathrm{km})$ of monthly combinations for each $5 \times 5^{\prime}$ grid cell polygon, and recalculated on-effort SPUE.

\section{Presence-only data}

Presence data came from 3 sources: (1) the NARWC database containing 6476 records spanning January to December 1966 to 2010, including oneffort, off-effort, and opportunistic whale sightings locations; (2) Allied Whale and Bar Harbor Whale Watch data containing 78 opportunistic sighting locations spanning June to October 1994 to 2010; and (3) Baumgartner \& Mate (2005) satellite tag data containing 328 tag locations from 18 tags, spanning July to October in 1989, 1990, 1991, and 2000. All satellite 
tag locations were used, as $68 \%$ of the poorest location quality records were within $7.5 \mathrm{~km}$ of the transmitter location (Baumgartner \& Mate 2005), which falls below the average distance traveled by a whale per day (see 'OPAKM'). This combination resulted in a total of 6882 presence records (for seasonal totals see Supplement 5 at www.int-res.com/articles/suppl/ n024p021_supp.pdf).

\section{Environmental variables}

We used 7 environmental variable datasets with the Maxent program. (1) Sea surface temperature: we downloaded monthly climatologies from Aqua MODIS nighttime from OceanColor's level 3 browser (oceancolor.gsfc.nasa.gov) at $4 \mathrm{~km}$ resolution and compiled seasonal averages using the raster calculator in ArcGIS 10.0. Sea surface temperature data was then re-sampled to $425 \mathrm{~m}$ resolution to match the finer resolution of the other environmental variables. (2) Depth: we downloaded the US Geological Survey (USGS) digital bathymetry of the Gulf of Maine from the USGS at $425 \mathrm{~m}$ resolution. (3) Distance to land: we calculated this in ArcGIS 10.0 at $425 \mathrm{~m}$ resolution. (4) Distance to physiographic areas in the Gulf of Maine: the Gulf of Maine Area Census of Marine Life has digitized these areas, including Georges Bank,
Georges Basin, Jordan Basin, Wilkinson Basin, Jeffrey's Ledge and the Coastal Shelf. We calculated distances to these areas in ArcGIS 10.0 at $425 \mathrm{~m}$ resolution. (5) Slope: we calculated this in ArcGIS 10.0 using the above-mentioned USGS bathymetry dataset at $425 \mathrm{~m}$ resolution. (6) Latitude and (7) Longitude grids: we created these in ArcGIS 10.0 at $425 \mathrm{~m}$ resolution.

\section{Modeling approach}

Fig. 2 illustrates the data processing method. We used on-effort whale sightings and corresponding effort data (trackline, $\mathrm{km}$ ) as input data to the OPAKM. We utilized presence-only records in conjunction with environmental co-variates (sea surface temperature, depth, distance to land, distance to physiographic regions, slope, latitude, and longitude) to create a probability of presence dataset in the program Maxent. We then summarized the probability of presence dataset to the $5 \times 5^{\prime}$ grid cell polygons, which served as input data in a GAKM. To combine the 2 models and produce a single output, we performed areal co-kriging, using the OPAKM output as a primary co-kriging variable and the GAKM output as a secondary co-kriging variable. Element details are fully described in the following sections.

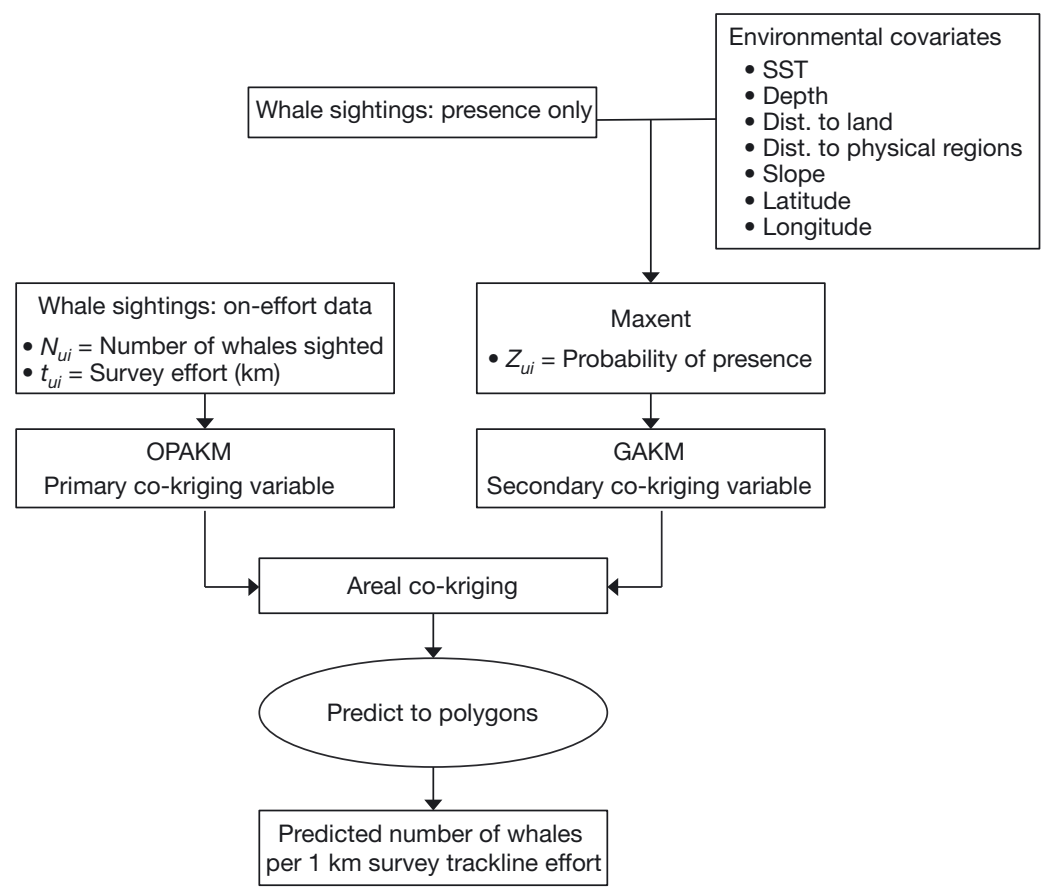

Fig. 2. Data processing module. Element details are fully described in the 'Methods'. SST: sea surface temperature; OPAKM: overdispersed Poisson areal kriging; GAKM: Gaussian areal kriging

\section{OPAKM}

We developed the OPAKM variable following methods described by Krivoruchko et al. (2011b). The input data for the OPAKM consisted of on-effort data (described above) summarized to $5 \times 5^{\prime}$ grid cell polygons with applied data values of number of whales sighted, $N_{u i}$ and amount of survey effort $(\mathrm{km}), t_{u i}$ for process $u$ in polygon $i$.

The OPAKM does not allow for a $t_{u i}$ of 0 and does not support reliable predictions into space containing no data; therefore, supplementary values needed to be added to $5 \times 5^{\prime}$ grid cells that contained null values (areas where there was no survey effort). To establish a value for $t_{u i}$ for null grid cells, we ran a Kaplan-Meier survival analysis in R statistical software (v 2. 14.0) on all seasonal datasets to determine where $t_{u i}$ (survey effort) was low 
enough to result in no whales sighted. Results were consistent across all seasons: a $t_{u i}$ of approximately $50 \mathrm{~km}$ or less per $5 \times 5^{\prime}$ grid cell resulted in no whale sightings (see Supplement 6 at www.int-res.com/ articles/suppl/n024p021_supp.pdf). As the OPAKM

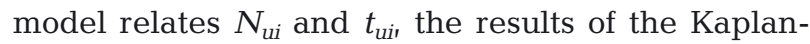
Meier survival analysis supported an assumption that all $t_{u i}<50 \mathrm{~km}$ should be normalized to $50 \mathrm{~km}$ to prevent over prediction in areas where $t_{u i}$ fell below this value. Therefore, we reclassified all grid cells with null $t_{u i}$ or $t_{u i}<50 \mathrm{~km}$ to $50 \mathrm{~km}$ and all grid cells with null $N_{u i}$ to 0 . In addition to resolving the issue of null values in $5 \times 5^{\prime}$ polygons occurring in ocean space, all $5 \times 5^{\prime}$ polygons falling on land were also void of data. To prevent whale predictions from spreading onto land, we created an artificial land barrier by inflating $t_{u i}$ to $10000 \mathrm{~km}$ and $N_{u i}$ to 0 .

In the OPAKM, the overdispersion parameter, $l$, is calculated using the negative binomial distribution. However, due to the nature of our data and the associated measurement error described earlier, the negative binomial distribution underestimated the variation, resulting in higher root-mean-square standardized errors. To correct for this, we determined 1 based on cross-validation, fitting the root-meansquare standardized error close to 1 .

As whales move freely, and are not bound to the $5 \times 5^{\prime}$ grid cells to which they were summarized, we used a smooth neighborhood type to create a more continuous surface. This neighborhood type uses a sigmoidal function to adjust the weights used with the measured values to predict values at each location based on a smoothing factor (a value between 0 and 1). We used the maximum smoothing factor of 1 and smoothing major and minor semiaxis of $50 \mathrm{~km}$, which was derived from the approximate average distance traveled by a whale per day calculated from the Baumgartner \& Mate (2005) satellite tag data.

\section{GAKM with Maxent}

We developed the GAKM variable following methods described by Krivoruchko et al. (2011b). The input data for the GAKM consisted of averaged probability of presence values, $Z_{u i r}$ per $5 \times 5^{\prime}$ grid cell polygon, $i$, derived in the program Maxent.

We ran the Maxent software version 3.3.3e at the spatial resolution of the input environmental variable datasets, $425 \mathrm{~m}$, on default settings (Supplement 7 at www.int-res.com/articles/suppl/n024p021_supp.pdf). Phillips \& Dudík (2008) found that the default settings performed well for presence-only datasets. The input sample data was all presence-only right whale locations (see 'Presence-only data'). The input environmental co-variates were: sea surface temperature, depth, distance to land, distance to physiographic areas, slope, latitude, and longitude (see 'Environmental variables'). The Maxent outputs resulted in a raster grid representing the probability of presence ranging on a log scale of 0 to 1 . We averaged the resulting outputs to the $5 \times 5^{\prime}$ grid cell polygons (Fig. 1). All $5 \times 5^{\prime}$ grid cell polygons covering land were reclassified to a value of 0 .

\section{Areal co-kriging}

We performed co-kriging to combine the OPAKM and GAKM, and produce a single output. The primary areal co-kriging variable was the OPAKM output and the secondary co-kriging variable was the GAKM output. A spherical model was used to fit the covariance based on the methods described by Krivoruchko et al. (2011b). We chose the spherical model over other model types after cross-validation yielded lower standard errors (see Table 2) and better fit the data (Supplement 8 at www.int-res.com/ articles/suppl/n024p021_supp.pdf).

We ran the predict to polygons tool on the resulting Geostatistical Analyst layers to predict the expected number of whales sighted per $1 \mathrm{~km}$ of survey trackline effort for each of the 524 fishing zone polygons. The polygon outputs were examined against all whale sighting locations to test for validation. We reclassified polygons with a predicted value of 0 that contained a whale sighting to half the standard error value in order to represent animal presence while not overestimating the prediction value. This affected $1.5 \%$ of all polygons (all data sets combined), mainly in June to November, which had characteristically more widely dispersed/sporadic whale sightings.

\section{RESULTS}

\section{Prediction values and errors}

The areal co-kriging prediction to polygons output represents the predicted number of right whales sighted per $1 \mathrm{~km}$ survey trackline effort for each of the 524 fishing zone polygons (summarized in Table 1). Results indicate that a higher number of whales occur in the study area from August to January and fewer between February and July. The spatial distributions of whales also vary temporally, exhibiting more con- 
Table 1. Summarized results and standard errors of the areal co-kriging model for the 524 polygons. Polygon prediction value represents the predicted number of right whales expected to be sighted per $1 \mathrm{~km}$ survey trackline effort

\begin{tabular}{|lccccccc|}
\hline \multirow{2}{*}{ Months } & \multicolumn{3}{c}{ Polygon predictions } & \multicolumn{3}{c|}{ Polygon standard error } \\
& Mean & Max. & Min. & Mean & Max. & Min. \\
\hline Dec/Jan & 0.0039 & 0.1397 & 0.0000 & 0.0027 & 0.0159 & 0.0000 \\
Feb/Mar & 0.0002 & 0.0070 & 0.0000 & 0.0000 & 0.0006 & 0.0000 \\
Apr/May & 0.0004 & 0.0079 & 0.0000 & 0.0001 & 0.0009 & 0.0000 \\
Jun/Jul & 0.0008 & 0.0156 & 0.0000 & 0.0032 & 0.0172 & 0.0000 \\
Aug/Sep & 0.0017 & 0.0696 & 0.0000 & 0.0025 & 0.0142 & 0.0000 \\
Oct/Nov & 0.0025 & 0.0564 & 0.0000 & 0.0002 & 0.0037 & 0.0000 \\
\hline
\end{tabular}

centrated clustering December through May, typically in Maine's southern coastal area, with greater dispersion throughout the study area from June through November (Fig. 3). Standard errors varied across different monthly aggregations, with smaller errors in February/March, April/May, and October/November and larger errors in December/January, June/July, and August/September (Table 1).
Upon validation, the areal co-kriging model produced root-mean-square standardized errors close to 1, indicating valid prediction errors. Mean standardized errors (the average difference between the measured and predicted values) were close to 0 , and root-mean-square error (indicating how closely the model predicts the measured value) and average standard errors (average of the prediction standard errors) were low, with little difference between them (Table 2).

\section{Maxent}

To assess our confidence in the right whale distribution results discussed in the above section, we needed assurance that the co-kriging variable derived from Maxent provided accurate results.
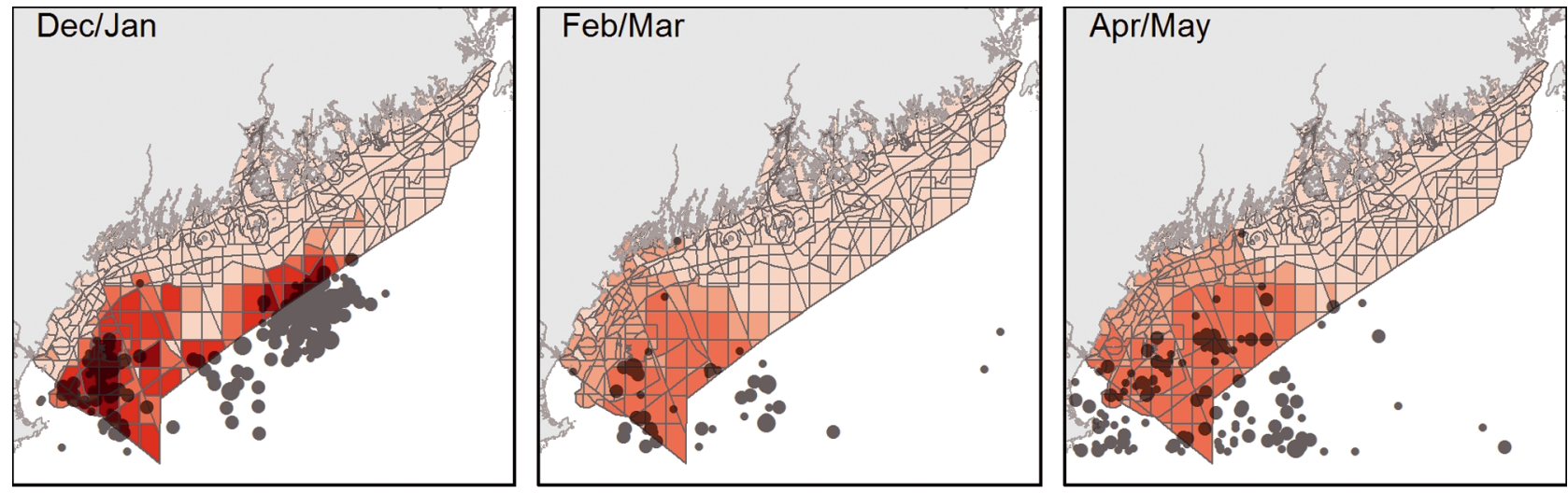

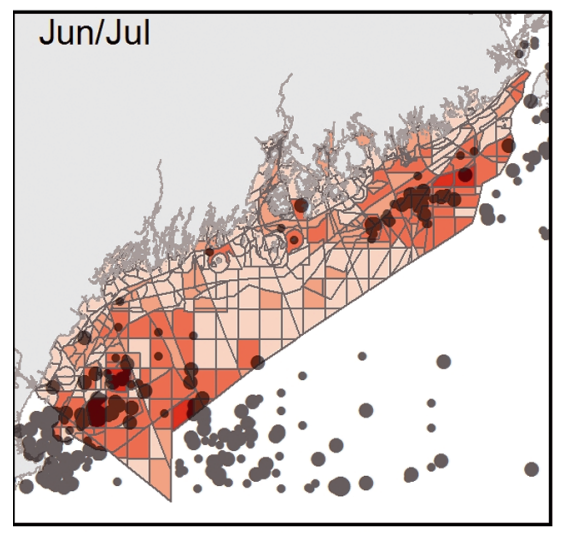

No. whales per $1000 \mathrm{~km}$ trackline

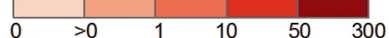

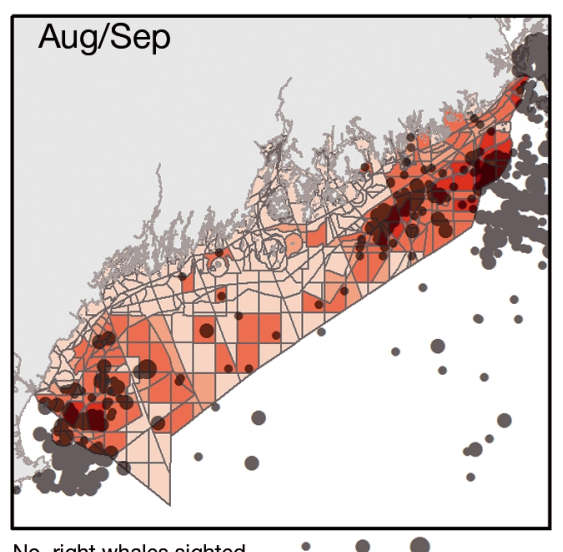

No. right whales sighted

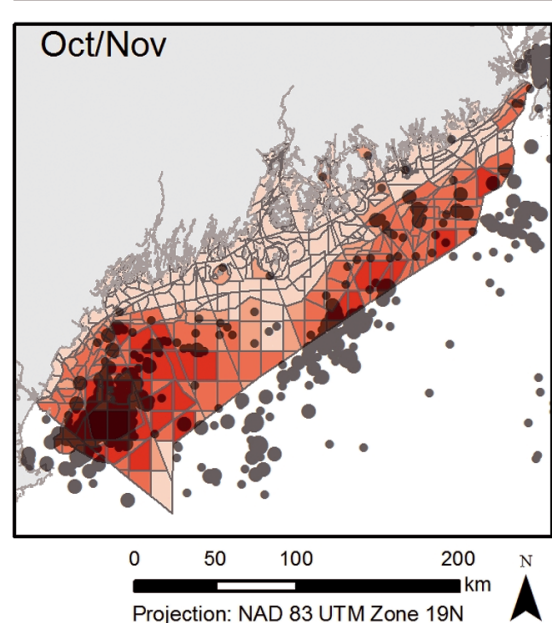

Fig. 3. Eubalaena glacialis. Estimated number of whales per $1000 \mathrm{~km}$ survey trackline effort, calculated by the areal co-kriging method. Whale sightings (O) are overlaid to exhibit how well the predicted values represent the whale occurrence data 
Table 2. Areal co-kriging geostatistical analyst layer error results

\begin{tabular}{|lcccc|}
\hline Months & $\begin{array}{c}\text { Root-mean-square } \\
\text { standardized }\end{array}$ & $\begin{array}{c}\text { Mean } \\
\text { standardized }\end{array}$ & $\begin{array}{c}\text { Average } \\
\text { SE }\end{array}$ & $\begin{array}{c}\text { Root-mean- } \\
\text { square }\end{array}$ \\
\hline Dec/Jan & 1.0021 & 0.0244 & 0.0208 & 0.0211 \\
Feb/Mar & 1.0025 & -0.0287 & 0.0056 & 0.0057 \\
Apr/May & 1.0038 & -0.0771 & 0.0046 & 0.0047 \\
Jun/Jul & 1.0033 & 0.0160 & 0.0159 & 0.0159 \\
Aug/Sep & 1.0023 & 0.0248 & 0.0163 & 0.0161 \\
Oct/Nov & 1.0000 & -0.0765 & 0.0134 & 0.0133 \\
\hline
\end{tabular}

Table 3. Maxent area under the receiver operating characteristic (ROC) curve (AUC) results

\begin{tabular}{|ll|}
\hline Months & AUC \\
\hline Dec/Jan & 0.964 \\
Feb/Mar & 0.957 \\
Apr/May & 0.942 \\
Jun/Jul & 0.945 \\
Aug/Sep & 0.910 \\
Oct/Nov & 0.912 \\
\hline
\end{tabular}

The output performance was measured by the area under the receiver operating characteristic (ROC) curve (AUC), which represents the probability that a randomly chosen presence location will be ranked above a randomly chosen background site. An AUC of 0.5 indicates a random ranking, whereas an AUC of 1.0 indicates a perfect ranking. Models are considered useful when their AUC values are above 0.75 (Phillips \& Dudík 2008). Although the AUC results in Table 3 indicate the output is not error free, all Maxent outputs performed well, with AUC measurements ranging from 0.910 to 0.964 (Table 3).

Estimates of relative contributions of the environmental co-variates to the Maxent model are given in Supplement 9 at www.int-res.com/articles/suppl/ n024p021_supp.pdf.

\section{DISCUSSION}

\section{Assessment of areal co-kriged predicted values versus raw data and on-effort SPUE}

Due to the nature of this highly mobile, cryptic, marine species, we may never know with complete certainty their distribution and numbers. This information, however, is becoming increasingly important to properly mitigate the anthropogenic effects on this Endangered species. To sufficiently characterize right whale distribution, it is vital to utilize all available data in order to limit data gaps. No method currently exists that incorporates all data types; therefore, we developed a method using an areal co-kriging model to utilize all available data and better characterize right whale distribution.

To assess whether the areal co-kriging method provides a better representation of whale distribution than that of the commonly used on-effort SPUE method, we compared the spatial distribution outputs of the 2 methods against whale occurrence data (on- and off-effort sightings) to determine which method better represents whale activity. Fig. 3 shows the number of whales expected to be sighted per $1000 \mathrm{~km}$ survey trackline effort for each fishing zone polygon predicted from the areal cokriging method. Fig. 4 shows the number of whales sighted (on-effort) per $1000 \mathrm{~km}$ survey trackline effort for each fishing zone polygon calculated with the SPUE method. For this assessment, whale sightings were overlaid to exhibit how well the predicted values from each method represent the known whale occurrence data.

For the purpose of this assessment, the term 'under-prediction' refers to any polygon that resulted in a predicted value of 0 or null, but is known to have whale occurrences. The term 'overprediction' refers to any polygon that resulted in a prediction value $>0$, but is where there have been no recorded whale sightings. Fig. 4 illustrates the extensive under-prediction of right whale presence resulting from the use of the on-effort SPUE method alone. Of the polygons that contained a whale sighting (a confirmed whale occurrence), 43 to $98 \%$ were calculated to have an on-effort SPUE value of 0 (some effort, but no whales) or null (no survey effort) (Table 4). The highest under-predictions occurred in June/July and August/September with 98 and $91 \%$, respectively, of the polygons with known right whale occurrences assigned 0 or null values. This supports the notion that on-effort SPUE alone is not a reliable representation of whale activity spatially.

In contrast, the areal co-kriging method does not produce this kind of under-prediction of spatial whale activity. Any polygon with a known whale occurrence has a predicted value $>0$. This method also, however, predicts whale activity in some polygons where there have been no recorded whale sightings. Although this could be considered an overprediction, we consider it valid in this case because: (1) the purpose of this model is to predict the likelihood of whale activity in a given polygon in the 

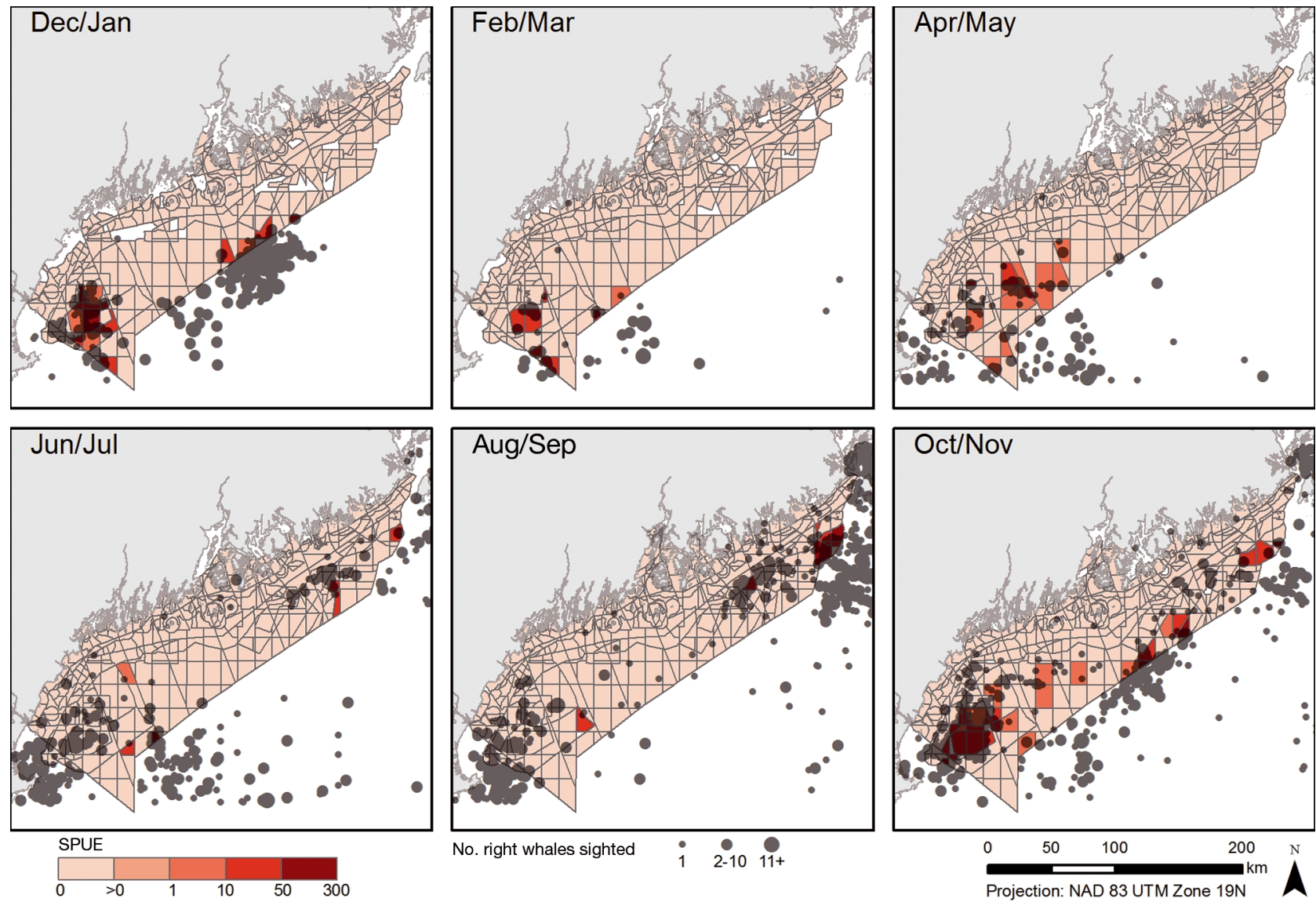

Fig. 4. Eubalaena glacialis. Right whale on-effort sightings per unit effort (SPUE). Values represent number of whales sighted (on-effort) per $1000 \mathrm{~km}$ survey trackline effort. Whale sightings (๑) are overlaid to exhibit how well the on-effort SPUE matches the whale occurrence data

Table 4. Percentage of polygons under-predicted. Under-predicted defined as polygons with on-effort sightings per unit effort (SPUE) calculated to be 0 (no whale present) or null (no data) where whales have been known to occur

\begin{tabular}{|c|c|c|c|}
\hline \multirow[t]{2}{*}{ Months } & \multicolumn{3}{|c|}{ No. of polygons } \\
\hline & $\begin{array}{l}\text { With whale } \\
\text { sighting }\end{array}$ & $\begin{array}{l}\text { With whale sighting } \\
\text { calculated at } 0 \text { or null }\end{array}$ & $\begin{array}{c}\text { Under- } \\
\text { prediction (\%) }\end{array}$ \\
\hline Dec/Jan & 30 & 13 & 43 \\
\hline Feb/Mar & 13 & 6 & 46 \\
\hline Apr/May & 32 & 17 & 53 \\
\hline Jun/Jul & 59 & 58 & 98 \\
\hline Aug/Sep & 94 & 86 & 91 \\
\hline Oct/Nov & 102 & 70 & 67 \\
\hline
\end{tabular}

method and on-effort SPUE method with that of on-effort sightings data only and on- and off-effort sightings data to evaluate for seasonal representation.

To compare the predicted values of the areal co-kriging and on-effort SPUE methods (in units of number of whales per $1 \mathrm{~km}$ survey trackline effort) with that of sightings data (in units of number of whales), we calculated the predicted number of whales present in a polygon $(N)$ for the 2 methods using the equation: $N=W \times$

future, not simply a direct representation of where they have been seen in the past; and (2) the polygons in question are clustered around polygons with known right whale presence (Fig. 3) and it is likely whales move into and between these areas.

We also compared the temporal distribution of whale activity predicted by the areal co-kriging
$(1 / \mathrm{TW}) \times A$, where $W$ is the estimated number of whales per $1 \mathrm{~km}$ survey trackline effort, TW is the effective track width of the survey (assumed here to be $5 \mathrm{~km})$, and $A$ is the area of the polygon $\left(\mathrm{km}^{2}\right)$. Per method, the estimated numbers across all polygons were summed to get the estimated number of whales for the study area. 


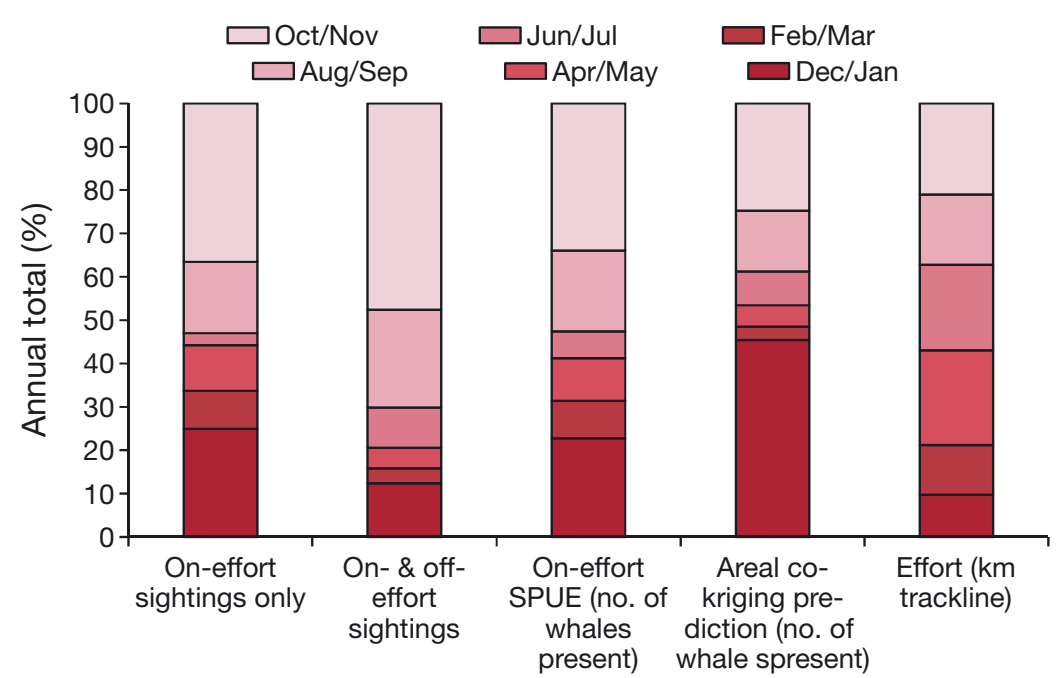

Fig. 5. Monthly aggregation percent contributions of each method's annual total

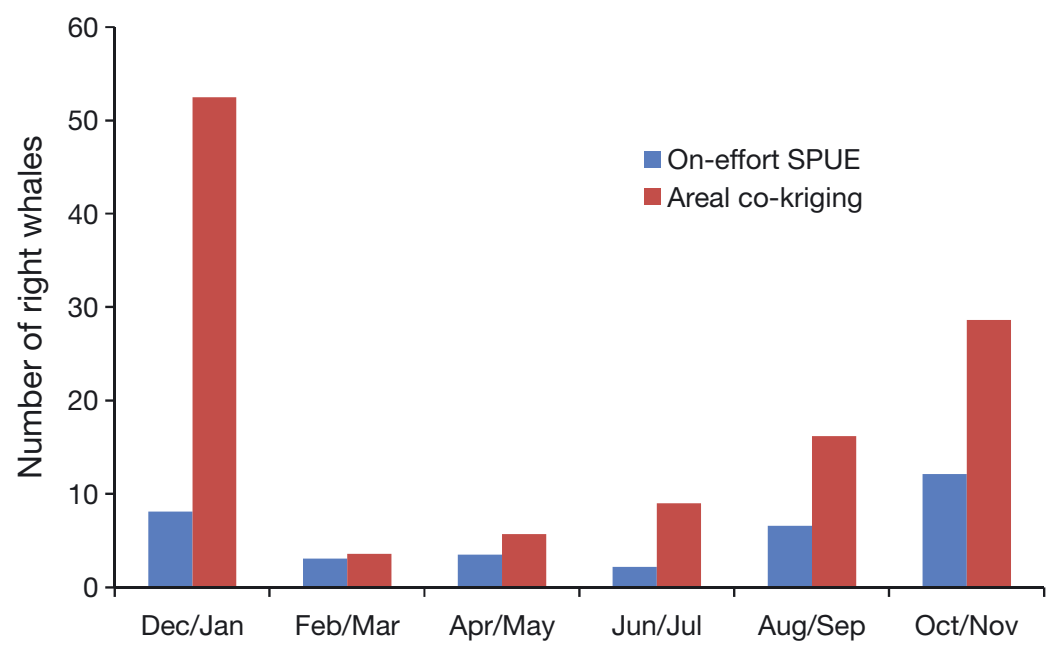

Fig. 6. Eubalaena glacialis. Number of right whales present in 524 polygon areas estimated by areal co-kriging method vs. on-effort sightings per unit effort (SPUE). (Effective survey track width assumed to be $5 \mathrm{~km}$ )

selves; however, the areal co-kriging method uses the high sightings values near the polygons to help inform the prediction, estimating higher whale activity values in the polygons. This concept remains consistent across seasons. The seasons with the highest predicted value differences between methods coincide with larger numbers of whale sightings close to, but falling outside, the 524 polygon boundaries (Figs. $3 \& 4$ ).

These analyses confirm that the whale activity predicted by the areal co-kriging approach falls within a reasonable aggregate range and is representative of the seasonal differences suggested by the raw on-effort and offeffort data. The areal co-kriged predicted output (Fig. 3) outperformed on-effort SPUE (Fig. 4) in spatially representing the whale distribution in comparison to the sightings data as it (1) incorporated all right whale sightings data (not only on-effort only sightings); (2) did not isolate polygons at their boundaries, allowing nearby polygons to inform each other in prediction, better representing whale movements across artificial boundaries; and (3) assigns reasonable whale activity estimates to polygons with no or limited systematic survey effort.

Areal co-kriging also provides standard errors associated with the predictive values, providing a level of confidence in our outputs which is not

The overall seasonal contributions across methods vary; however, the general patterns remain consistent (Fig. 5). The areal co-kriging predicts a greater fraction of total whale activity in December/January than the other methods; however, this seems appropriate due to this method's predicted aggregate level of whale activity discussed below.

Lastly, we compared the aggregate level of whale activity predicted by the 2 methods (Fig. 6). Areal cokriging produced a higher level of whale activity than that predicted by on-effort SPUE, particularly in December/January, This is likely due to the December/ January data containing many whales falling just outside the boundaries of the 524 output polygons (Fig. 3). On-effort SPUE ignores these sightings, as they do not fall within the polygon boundaries themavailable with the on-effort SPUE method. While the predicted value error ranges were large in December/ January, June/July, and August/September, the rootmean-square standardized errors were close to 1 , giving us confidence in these ranges. Overall, the areal co-kriged method produced a more complete spatial and temporal representation of whale activity compared to on-effort SPUE.

Acknowledgements. We acknowledge and thank all people and affiliations whose help made this work possible: P. McCarron and H. Tetreault, Maine Lobstermen's Association; Dr. C. Brehme, Keene State College; Dr. R. Kenney, University of Rhode Island; E. Krause, ESRI; North Atlantic Right Whale Consortium; New England Aquarium; Woods Hole Oceanographic Institution; as well as our funding agency, NOAA Sea Grant. 


\section{LITERATURE CITED}

Baumgartner MF, Mate BR (2005) Summer and fall habitat of North Atlantic right whales (Eubalaena glacialis) inferred from satellite telemetry. Can J Fish Aquat Sci 62: 527-543

Bolstad P (2008) GIS fundamentals. A first text on geographic information systems, 3rd edn. Eider Press, White Bear Lake, MN

Brehme C, McCarron P, Tetrault H (in press) A model of the spatial distribution of lobster fishing gear along the Maine coast using local knowledge and dasymetric mapping. Prof Geogr

Brown M (2002) Proposed changes would make Canadian waters safer for right whales. Right Whale News 9(3). www.narwc.org/pdf/rwn/rwaug02.pdf (accessed 12 June 2012)

Franklin J (2009) Mapping species distributions: spatial inference and prediction. Cambridge University Press, New York, NY

Fujiwara M, Caswell H (2001) Demography of the endangered North Atlantic right whale. Nature 414:537-541

Hilbe JM (2007) Negative binomial regression. Cambridge University Press, Cambridge

Kenney RD (2010) The North Atlantic right whale consortium database: a guide for users and contributors. North Atlantic Right Whale Consortium Reference Document 2010-01, University of Rhode Island, Graduate School of Oceanography, Narragansett, RI

Kenney RD (2012) Estimating minimum SPUE values for right and humpback whales in northeast areas with low survey effort. Report to Marine Mammal Commission, University of Rhode Island, Graduate School of Oceanography, Narragansett, RI. P.O. No. MMC12 065

Knowlton AR, Kraus SD (2001) Mortality and serious injury of northern right whales (Eubalaena glacialis) in the western North Atlantic Ocean. J Cetacean Res Manag 2(Special Issue):193-208

Kraus SD, Brown MW, Caswell H, Clark CW and others (2005) North Atlantic right whales in crisis. Science 309: 561-562

Krivoruchko K, Gribov A, Krause E (2011a) Multivariate areal interpolation for continuous and count data. Procedia Environ Sci 3:14-19

Krivoruchko K, Gribov A, Krause E (2011b) Interpolation of data collected in polygons. JSM 2011 Proceedings. American Statistical Association, Section on Statistics

Editorial responsibility: Philip Stephens,

Durham, UK and the Environment, Alexandria, VA, p 1914-1928

Martin TG, Wintle BA, Rhodes JR, Kuhnert PM and others (2005) Zero tolerance ecology: improving ecological inference by modeling the source of zero observations. Ecol Lett 8:1235-1246

Nichols OC, Kite-Powell HL (2005) Analysis of risk to North Atlantic right whales (Eubalaena glacialis) from shipping traffic in Cape Cod Bay. Report to NOAA Fisheries, Woods Hole Oceanographic Institution, Center for Coastal Studies, Provincetown, MA. Award No. NA03NMF4720489

NARWC (North Atlantic Right Whale Consortium) (2012) Sightings database. New England Aquarium, Boston, MA

Paxton CGM, Machenzie M, Burt ML, Rexstad E, Thomas L (2011) Phase II data analysis of joint cetacean protocol data resource. Report to Joint Nature Conservation Committee, University of St. Andrews, Centre for Research into Ecological and Environmental Modelling, Contract No. C11-0207-0421

Pettis H (2011) North Atlantic Right Whale Consortium 2011 Annual Report Card. Report to the North Atlantic Right Whale Consortium, John H. Prescott Marine Laboratory, New England Aquarium, Boston, MA

Phillips SJ, Dudík M (2008) Modeling of species distributions with Maxent: new extensions and a comprehensive evaluation. Ecology 31:161-175

Phillips SJ, Anderson RP, Schapire RE (2006) Maximum entropy modeling of species geographic distributions. Ecol Model 190:231-259

Pike DG, Gunnlaugsson T, Víkingsson G (2009) T-NASS Icelandic aerial survey: Survey report and preliminary abundance estimate for minke whales. SC/60/PFI12 presented to the Scientific Committee of the International Whaling Commission, June 2008

Provincetown Center for Coastal Studies (PCCS) (2009) Shipping lanes and whales. www.coastalstudies.org/ what-we-do/public-policy/bay-of-fundy.htm (accessed 10 June 2012)

Reilly SB, Bannister JL, Best PB, Brown M and others (2012) Eubalaena glacialis. In: IUCN 2013. IUCN Red List of Threatened Species. Version 2013.2. www.iucnredlist.org (accessed 19 March 2014)

van der Hoop JM, Moore MJ, Barco SG, Cole TVN and others (2013) Assessment of management to mitigate anthropogenic effects on large whales. Conserv Biol 27: 121-133

Submitted: June 10, 2013; Accepted: January 10, 2014

Proofs received from author(s): March 19, 2014 